OPEN ACCESS

Edited by: Dalena Van Heugten - Van Der Kloet, Oxford Brookes University, UK

Reviewed by:

Jim Hopkins,

University College London, UK Steven Jay Lynn,

Binghamton University, USA

*Correspondence: Nirit Soffer-Dudek soffern@bgu.ac.il

Specialty section: This article was submitted to Psychopathology, a section of the journal Frontiers in Psychology

Received: 12 October 2016 Accepted: 24 April 2017 Published: 10 May 2017

Citation:

Soffer-Dudek N (2017) Arousal in Nocturnal Consciousness: How Dream- and Sleep-Experiences May Inform Us of Poor Sleep Quality,

Stress, and Psychopathology. Front. Psychol. 8:733. doi: 10.3389/fpsyg.2017.00733

\section{Arousal in Nocturnal Consciousness: How Dream- and Sleep-Experiences May Inform Us of Poor Sleep Quality, Stress, and Psychopathology}

\author{
Nirit Soffer-Dudek* \\ Consciousness and Psychopathology Laboratory, Department of Psychology, Ben-Gurion University of the Negev, \\ Beer-Sheva, Israel
}

The term "sleep experiences," coined by Watson (2001), denotes an array of unusual nocturnal consciousness phenomena; for example, nightmares, vivid or recurrent dreams, hypnagogic hallucinations, dreams of falling or flying, confusional arousals, and lucid dreams. Excluding the latter, these experiences reflect a single factor of atypical oneiric cognitions ("general sleep experiences"). The current study is an opinionated mini-review on the associations of this factor-measured with the lowa sleep experiences survey (ISES, Watson, 2001) - with psychopathological symptoms and stress. Findings support a strong relation between psychological distress and general sleep experiences. It is suggested that that they should be viewed as a sleep disturbance; they seem to represent involuntary intrusions of wakefulness into sleep, resulting in aroused sleep. These intrusions may stem from excessively thin boundaries between consciousness states (e.g., "transliminality"), or, conversely, they may follow an attempt at disconnecting mental elements (e.g., dissociation), which paradoxically results in a "rebound effect." The extent to which unusual dreaming is experienced as intrusive, rather than controlled, may explain why general sleep experiences are related to psychopathology, whereas lucid dreams are related to psychological resilience. In conclusion, the exploration of the interplay between psychopathology and sleep should be expanded from focusing almost exclusively on quantitative aspects (e.g., sleep efficiency, latency) to including qualitative conscious experiences which may reflect poor sleep quality. Taking into account nocturnal consciousness-including unusual dreaming and permeable sleep-wake boundaries - may unveil rich information on night-time emotional states and broaden our definition of poor sleep quality.

Keywords: sleep experiences, dreaming, sleep quality, psychopathology, distress, nightmares, hypnagogic hallucinations, sleep-wake disorders

A vast body of literature shows that sleep problems are related to an array of psychopathological disorders, including depression, bipolar disorder, anxiety disorders, posttraumatic stress disorder (PTSD), obsessive-compulsive disorder, schizophrenia, dissociation, alcoholism, eating disorders, attention deficit hyperactivity disorder, dementia, and autism (Benca et al., 1992; Chouinard et al., 2004; Spoormaker and Montgomery, 2008; Cortese et al., 2009; Sedky et al., 2014; van Heugten-van der Kloet et al., 2014a; Díaz-Román et al., 2015; Nota et al., 2015). Most 
studies on psychopathology and sleep assess sleep quality or disruption in terms of one's ability to fall asleep with ease and sleep through the night uninterrupted. Therefore, research has mostly relied on quantitative measures. These include, for example, total/true sleep time, sleep efficiency, sleep latency, wake after sleep onset, and number of awakenings (e.g., Elrod and Hood, 2015; Ng et al., 2015). Indeed, these variables play a central role in psychopathology and have the advantage of possible objective assessment (e.g., polysomnography, actigraphy).

However, the focus on quantitative measures is intertwined with a certain neglect of subjective-or qualitative-aspects of the sleeper's consciousness, such as dream characteristics. This relative neglect is evident in the Diagnostic and Statistical Manual of Mental Disorders, Fifth Edition (DSM-5; American Psychiatric Association, 2013); out of numerous disorders of sleep-wake processes, spanning problems with the amount and timing of sleep, breathing-disordered sleep, and parasomnias (e.g., sleepwalking), only one, namely, nightmare disorder (ND), is primarily concerned with an alteration in dreaming. Similarly, while symptoms involving quantitative sleep alterations appear in numerous diagnoses in other chapters of the manual (e.g., mood disorders), qualitative nocturnal experiences are hardly addressed. Other than "recurrent distressing dreams" related to traumatic content in the diagnosis of PTSD (American Psychiatric Association, 2013), dreaming does not play a major role in the DSM-5. Thus, although the field of Psychology is interested not just in behavior but also in subjective experience, it seems that current views of mental health do not tend to take into account characteristics of nocturnal consciousness when defining or diagnosing psychopathology. Granted, dream research suffers from the problem of subjectivity, and dream reports may be unreliable and open to bias (see Schwartz and Maquet, 2002, for a review of methodological problems in dream research). Yet, this problem may be reduced by conducting rigorous studies exploring relationships between dream- and sleep-experiences and emotion with daily diaries (e.g., Soffer-Dudek and Shahar, 2011), or by lexical analysis of dreams (Schwartz and Maquet, 2002). I assert that paying attention to nocturnal subjective experience is informative and worthwhile. The current investigation is a qualitative minireview on the relation between psychopathology and a trait representing unique nocturnal consciousness.

\section{NOCTURNAL CONSCIOUSNESS AND ITS IMPORTANCE FOR THE EXPLORATION OF PSYCHOPATHOLOGY}

By using the term "nocturnal consciousness," rather than "dreaming," I refer to subjective experience throughout various sleep stages and sleep-wake transitions. Specifically, I wish to emphasize: (1) that I am not merely considering the content of dreams, but also their structural or formal aspects, such as repetitiveness, vividness, and bizarreness; and (2) that the review

Abbreviations: GSEs, general sleep experiences; LDs, lucid dreams; PTSD, posttraumatic stress disorder; ND, nightmare disorder. is not limited to typical REM dreams, but also includes non-REM mentation, which may be experienced as "thoughts" (McNamara et al., 2010), as well as sleep-wake transition phenomena such as sleep paralysis, hypnagogic hallucinations, and confusion upon awakening. Notably, the present review is meant to supplement and extend the already-established literature on non-REM sleepwake disorders (sleepwalking, night terrors). These disorders, representing arousal in sleep, are strongly related to stress and psychopathology (Schenck and Mahowald, 2005).

Do alterations in nocturnal consciousness play a significant role in psychopathology? Indeed, there is ample evidence that dream characteristics are associated with several psychopathological symptoms. For example, nightmares are related to emotional distress, trauma, and personality disorders (e.g., Zadra and Donderi, 2000; Levin and Nielsen, 2009; Davis et al., 2011; Casement and Swanson, 2012; Schredl, 2016), and share a specific association with suicidality (Cukrowicz et al., 2006; Sjöström et al., 2007; Pigeon et al., 2012). Suicidality is also related to a reduction in dream-like quality of dream content reports between the first and second half of the night (Agargun and Cartwright, 2003). Alterations in dreaming seem to play a part in psychosis as well (D'Agostino et al., 2012, 2013; Cavallotti et al., 2014). In fact, the dream sleep stage (i.e., REM sleep), has been suggested as a model for schizophrenia (Gottesmann, 2006), and there is some evidence that psychosis may be conceptualized as sleeping mentation entering the waking state (e.g., Sponheim et al., 1994). The various nocturnal consciousness characteristics that have been related to stress, negative emotion, or psychopathological symptoms include-but are not limited to-traumatic and non-traumatic nightmares (e.g., van der Kolk et al., 1984; Hartmann, 1998; Levin, 1998; Cukrowicz et al., 2006; Pigeon et al., 2012), recurrent dreams (Zadra et al., 1997-1998; Duke and Davidson, 2002), falling dreams (e.g., Kroth et al., 2002; Schredl, 2007), dream bizarreness (e.g., Cavallotti et al., 2014), and hypnagogic hallucinations (Ohayon et al., 1996; Ohayon, 2000; Koffel, 2011).

Additionally, in recent years a broad trait of unique dream characteristics has been strongly and repeatedly linked with distress. In 2001, David Watson analyzed items addressing various aspects of unique dream and sleep-wake transition experiences, resulting in two factors for the "Iowa Sleep Experiences Survey” (ISES; Watson, 2001). Fifteen items loaded onto a non-specific factor, which includes an array of unusual dreams and sleep-wake phenomena (henceforth labeled general sleep experiences; GSEs; Watson, 2001), such as remembering dreams, nightmares, recurrent dreams, vivid dreams, dreams of flying or falling, confusion between dreams and reality, false awakenings (i.e., awakening within the dream), dreams of dying, and hypnagogic hallucinations. Three items loaded on a separate factor, pertaining to the experience of lucidity in dreams (i.e., awareness of the fact of dreaming, while maintaining the sleep state, and control over dream events). This subscale (LDs) is moderately related to GSEs (e.g., $r=0.42, p<0.001$, SofferDudek and Shahar, 2009), suggesting that they are not identical. GSEs (but not LDs) have repeatedly been associated with negative emotionality, stress, and psychopathological symptoms. Notably, studies that explored relationships of psychopathology with 
individual ISES items (e.g., Watson, 2001; Soffer-Dudek et al., 2011a) found relations with most items, suggesting that the relation of GSEs with psychopathology does not stem specifically from the nightmare item or any other single item. Table 1 reviews research that examines the relationship between GSEs (as measures with the ISES) along with measure(s) of negative emotion, stress, or psychopathological symptoms ${ }^{1}$.

As evident from the table, GSEs are positively associated with various psychopathological symptoms. The first types of symptoms associated with GSEs were dissociative experiences (Watson, 2001, 2003; Giesbrecht and Merckelbach, 2004, 2006a; Fassler et al., 2006) and schizotypy (Watson, 2001, 2003). On the basis of these relations, Watson concluded that the constructs form a common domain involving unusual cognitions and perceptions in waking and in sleep (Watson, 2001). Koffel and Watson (2009) further clarified that GSEs are characteristic of a psychopathological tendency for oddity, including magical ideation, suspiciousness, ideas of reference, unusual perceptions, and odd speech, behaviors, and beliefs. They reviewed findings of higher correlations of GSEs with dissociation (Koffel and Watson, 2009) and with dissociation and schizotypy (Watson, 2001), compared with negative affectivity and obsessivecompulsive symptoms (Koffel and Watson, 2009) or with neuroticism (Watson, 2001; see also Knox and Lynn, 2014). Hence, they suggested that GSEs are specific to dissociation and schizotypy, whereas insomnia and lassitude are specific to depression and anxiety (Koffel and Watson, 2009; Koffel, 2011).

However, Fassler et al. (2006) found that effect sizes of GSEs with dissociation were similar in magnitude to those with negative emotion. Subsequent research on GSEs pointed to strong non-specific associations with a wide array of psychological distress symptoms (Soffer-Dudek and Shahar, 2009, 2010, 2011; Watson et al., 2015; Soffer-Dudek, 2016). Moreover, this relationship has been extended from student samples to clinical samples (Soffer-Dudek et al., 2011a; Watson et al., 2015), including not only self-report methods but also using rigorous interview-based diagnoses (Watson et al., 2015). GSEs do not merely relate concurrently to distress, but also longitudinally. Specifically, psychological symptoms (a general distress score, as well as several subscales: somatization, obsessive-compulsive symptoms, depression, hostility, paranoid ideation, and psychoticism) prospectively predicted an elevation in GSEs across a 3 month interval (Soffer-Dudek and Shahar, 2009). Moreover, baseline GSEs were a potent prospective predictor of an elevation in psychopathological symptoms following exposure to terror 3 years later (Soffer-Dudek, 2016). Studies using other measures focusing on specific unusual sleep events also support these relations with distress. For example, in a study on adults reporting childhood trauma, McNally and Clancy (2005) found that sleep paralysis is related to both depression and dissociation, with similar effect sizes. In addition, nightmares show moderate to strong correlations with depression and anxiety in student and psychiatric samples (e.g., Koffel and Watson, 2010).

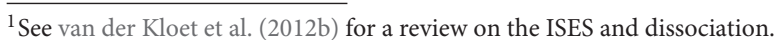

The two views of GSEs, namely, as an altered consciousness trait pertaining to unusual cognitions and as a manifestation of psychological distress, are not necessarily contradictory. One study integrated them by demonstrating a symmetrical diathesis-stress interaction, according to which the effect of trait dissociation on daily GSEs was present only in the face of high daily stress, and the effect of daily stress on GSEs existed only among those high in trait dissociation (Soffer-Dudek and Shahar, 2011). Thus, it seems that for individuals who are prone to experience unusual cognitions, psychological distress may be manifested in alterations in nocturnal consciousness.

\section{GSES AS DISRUPTED SLEEP}

The relationship of GSEs with various forms of psychopathological distress, reviewed in Table 1, suggests that GSEs may represent a form of distressed sleep. This raises a question, namely: Should there be some correlation between GSEs and traditional (quantitative) measures of disturbed sleep quality? Or are GSEs an entirely different, independent form of sleep disturbance? Research has been equivocal on this matter. Several studies did find a relation (Kucukgoncu et al., 2010; Soffer-Dudek and Shahar, 2011; van Heugten-van der Kloet et al., 2014a, 2015a,b; Soffer-Dudek, 2016). However, others did not (Watson, 2003; Van Der Kloet et al., 2013). Knox and Lynn (2014) found it only in one of their two samples. These null findings may be rooted in the fact that Van Der Kloet et al. (2013) and Watson (2003) used the total ISES score, which included LDs, and that Watson (2003) and Knox and Lynn (2014) did not separate sleep quality from sleep duration. In a rigorous daily study, Soffer-Dudek and Shahar (2011) showed that elevated GSEs were related to poor sleep quality, but also to long sleep duration (see also van Heugten-van der Kloet et al., 2015a, for somewhat similar results).

GSEs as sleep disruptions have been conceptualized as arousal and hypervigilance permeating the dream state (SofferDudek and Shahar, 2011). This conceptualization is similar to the classic view of disrupted sleep, according to which, vigilance to threat pulls one away from sleep and toward waking (e.g., Dahl, 1996); except that it does not view sleep and waking as mutually exclusive states, but rather posits that arousal may exert its influence on consciousness even without waking up the sleeper. Undeniably, non-REM parasomnias (e.g., sleepwalking) are hybrid sleep-wake states; GSEs may represent the corresponding REM sleep phenomena (e.g., elevated dream recall, nightmares, hypnagogic hallucinations, intensely kinesthetic dreams, vivid dreams, confusional arousals, false awakenings, and recurrent dreams, characterized by increased access to memory). Indeed, individuals suffering from insomnia show greater brain metabolism during sleep (Nofzinger et al., 2004), and higher frequency EEG activity during sleep onset and non-REM sleep (e.g., Perlis et al., 2001), especially in the face of stress (Hall et al., 2007). Moreover, stress and worry carry prolonged cardiovascular effects into sleep, independent of sleep quality, which have been labeled "unconscious worry" (Brosschot et al., 2007). Importantly, some individuals seem to 


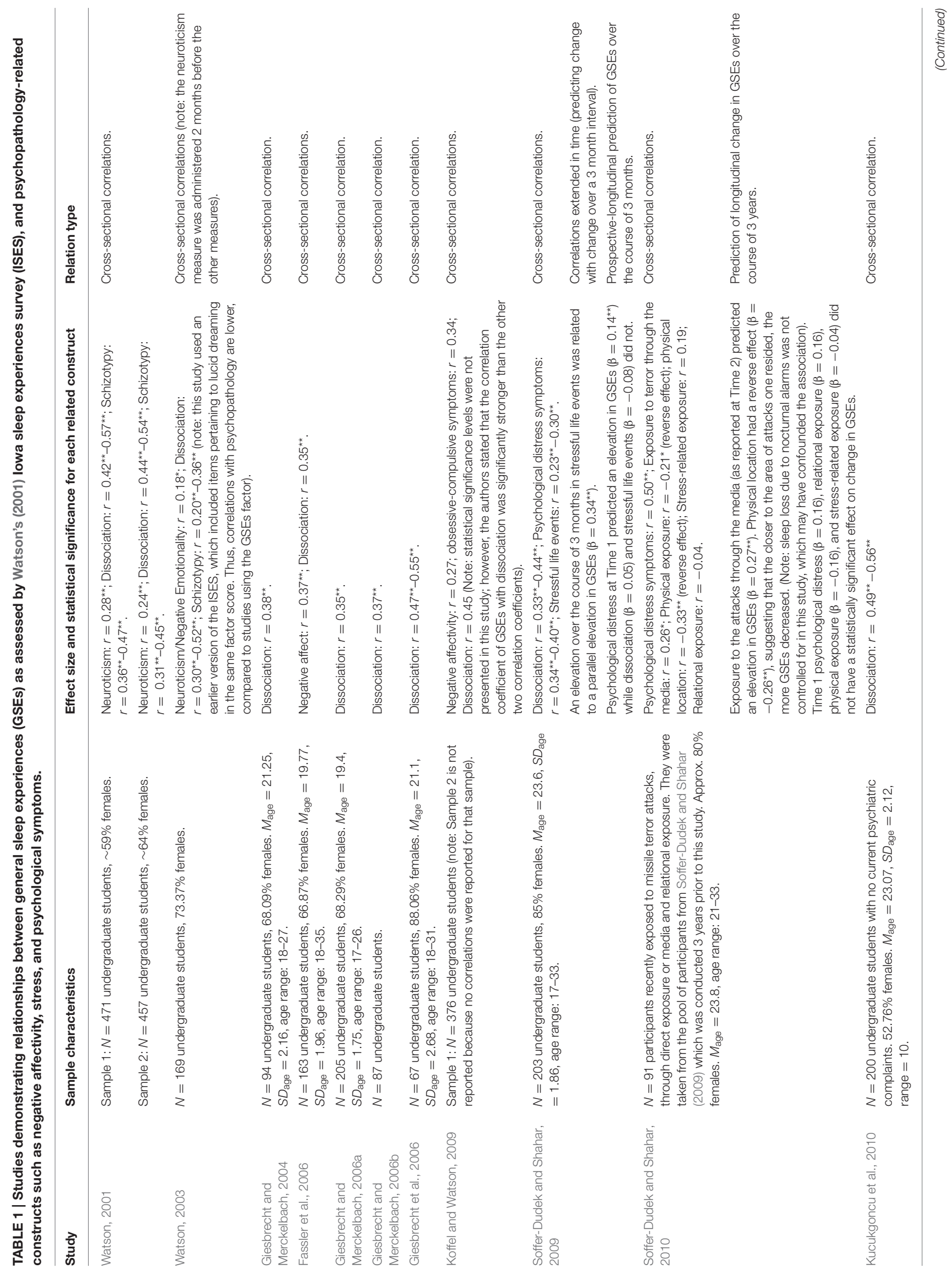




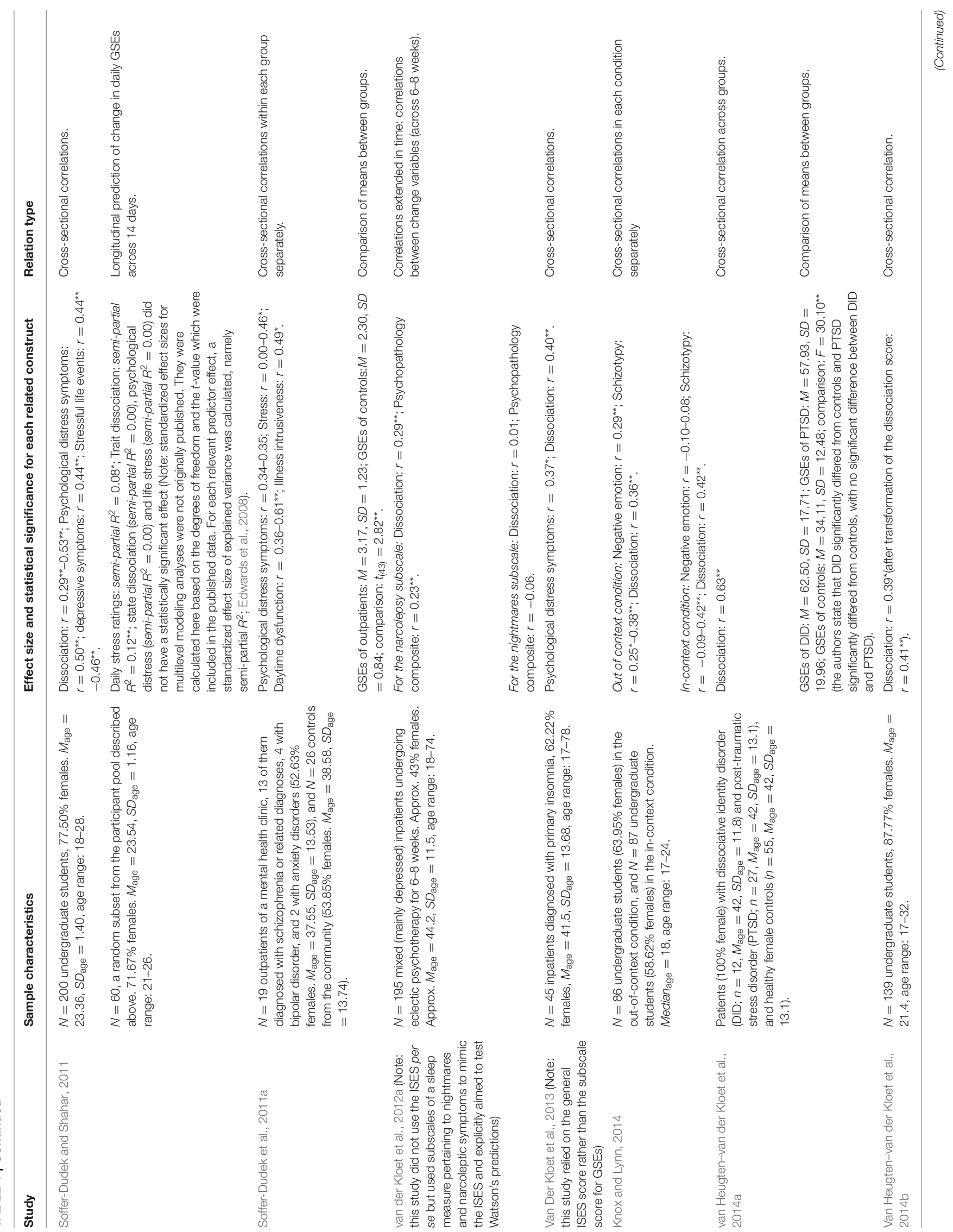



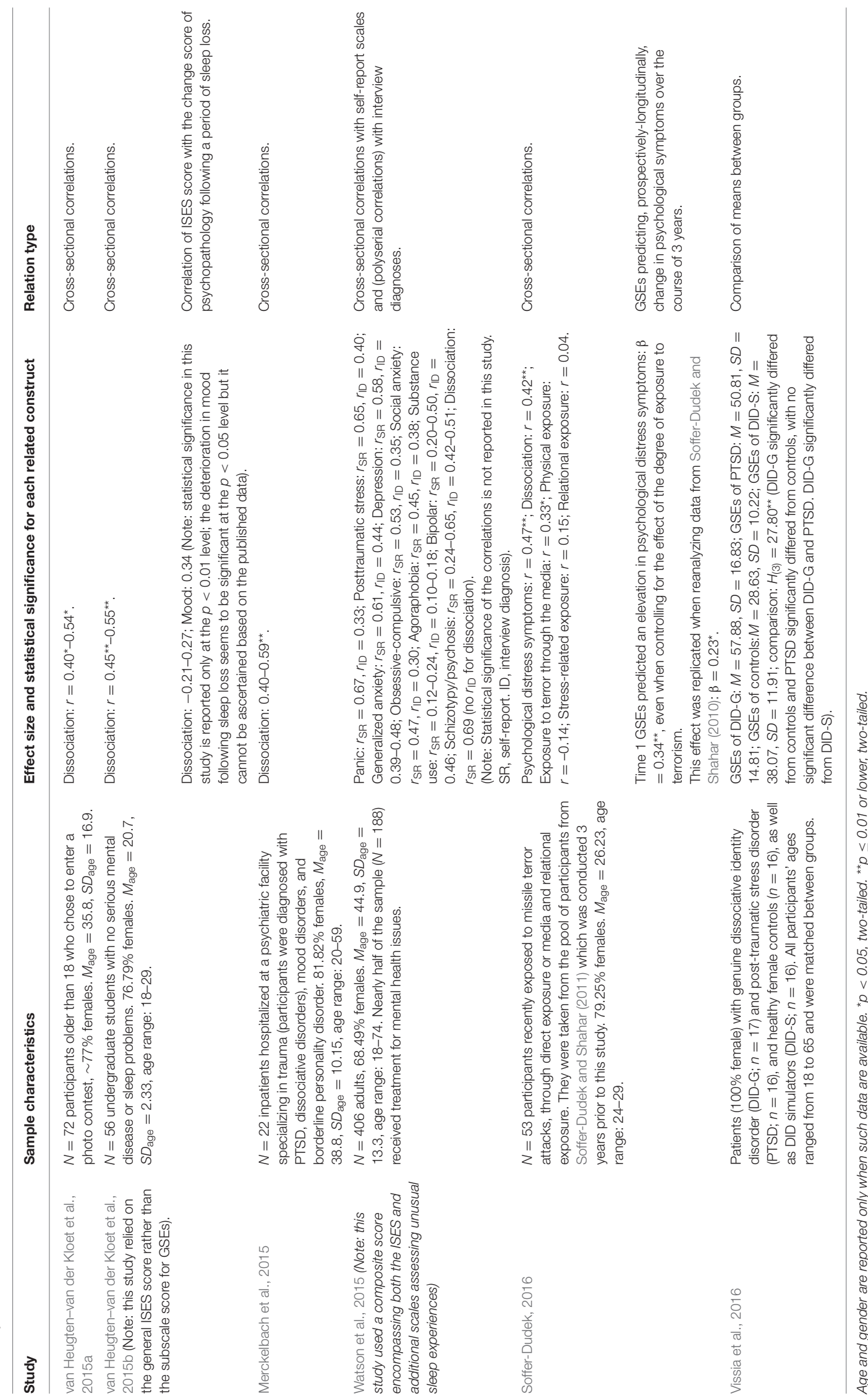

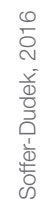

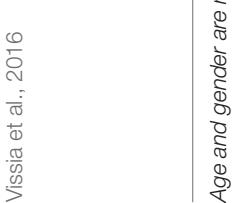


be especially capable of lingering in mixed sleep-wake states, including dissociative experiences and parasomnias (Mahowald and Schenck, 2001; Giesbrecht et al., 2008; Koffel and Watson, 2009; van der Kloet et al., 2012b). Dissociation and GSEs may reflect a reciprocal process in which sleep and waking intrude into one another. The conceptualization of GSEs as an intrusion of waking into sleep is concordant with the finding that among patients with severe psychopathology, GSEs were related to their experience of the mental illness as intrusive (Soffer-Dudek et al., 2011a).

\section{THE PARADOX OF INTRUSION: NOTES ON THE TRAITS THAT LEAD TO GSES}

Enduring the intrusion of waking within dreaming suggests increased fusion and association between consciousness states. Watson (2001) proposed that the trait responsible for the continuum of unusual cognitions may be "thin boundaries"a tendency for ideas, emotions, memories, and sensations to associate or merge (Hartmann, 1991), or "transliminality"a similar tendency for psychological material to pass fluidly between consciousness thresholds (Lange et al., 2000). Indeed, GSEs are related to transliminalty (Soffer-Dudek and Shahar, 2009) and synaesthesia (Terhune, 2009). Yet, dissociation, which is closely related to GSEs, is a state of separation of mental elements, as can be inferred from its name. Dissociative absorption, for example, is defined as the total allocation of attention to a stimulus while being oblivious to surrounding stimuli (Soffer-Dudek et al., 2015). How can these definitions harmoniously co-exist?

A possible explanation for this seeming discrepancy is the dream rebound effect of avoidance. Specifically, actively attempting not to think about a stimulus (e.g., a white bear), results in increased dreaming about that object (Wegner et al., 2004; Taylor and Bryant, 2007; Schmidt and Gendolla, 2008; Kröner-Borowik et al., 2013; Malinowski, 2016), and especially when facing cognitive load (Bryant et al., 2011). Ironically, suppressing thoughts leads to attempts at monitoring those thoughts, which in turn generate intrusions, resulting in an increase in the occurrence of the thoughts (Wegner, 1994; Wenzlaff and Wegner, 2000). This pertains to the core dynamics of PTSD: The more the individual exerts effort in avoiding thoughts of the trauma, the more they will appear uninvited, as dissociative flashbacks and nightmares. These processes may similarly govern the occurrence of GSEs: Intrusion of arousal into dreaming may be rooted not only in a tendency for increased association of mental elements (i.e., thin boundaries, enhanced continuity between waking and dreaming), but also in a tendency for increased avoidance and attempts at separating consciousness elements from each other (e.g., memories and emotions), such as dissociative mechanisms, which ironically also result in increased intrusion.

The idea that GSEs are experienced as an uncontrolled intrusion into sleep may be the explanation for the relative lack of findings on LDs and psychopathology. Specifically, LDs are also a "mixed state" between waking and sleeping (Mahowald and Schenck, 2001; Voss et al., 2009); they are even related to blurred boundaries between reality and fantasy (Corlett et al., 2014). However, they do not show the same strong and persistent relation with psychopathology and stress that GSEs do (e.g., Soffer-Dudek and Shahar, 2009; Soffer-Dudek, 2016). This difference may stem from the subjective feeling of control characterizing many LDs, in which the plot of the dream may be volitionally influenced by the dreamer. Indeed, LDs have been related to an internal locus of control (Blagrove and Tucker, 1994; Blagrove and Hartnell, 2000; Patrick and Durndell, 2004) and to psychological resilience in the face of exposure to terror (Soffer-Dudek et al., 2011b).

In contrast, GSEs seem to resemble uncontrolled nocturnal rumination: the uninhibited lingering of distress in the sleeper's consciousness. Indeed, during stressful military conflicts, GSEs are related to a somewhat ruminative inclination to keep watching the news, even though it causes the watcher distress (Soffer-Dudek and Shahar, 2010; Soffer-Dudek, 2016). This tendency to hold on to distress, whether during daytime or nighttime, may be the explanation for some enigmatic findings. Specifically, Soffer-Dudek and Sadeh (2013) found that self-reported unusual dreaming in children predicted an increase in parental ratings of the children's behavior problems (internalizing and externalizing) from age 10 to 12; this suggested that unusual dreaming identified somewhat covert distress or potential for psychopathology, undetectable by parents at age 10. Similarly, Soffer-Dudek (2016) also demonstrated that GSEs may reflect covert aspects of distress. Specifically, baseline GSEs prospectively predicted an elevation in psychological distress following exposure to terror attacks 3 years later, over and above the participants' own account of how much they were exposed and distressed by the attacks. GSEs may identify potential future distress, because they represent the inclination to ruminatively and uncontrollably linger in a mixed sleepwake state, an inclination which places the individual at risk for psychopathology ${ }^{2}$.

\section{LIMITATIONS, FUTURE DIRECTIONS, AND CONCLUSIONS}

A major methodological limitation of the research reviewed is that it is largely questionnaire-based; hence relationships may suffer from inflation due to biased reporting and shared method variance. Notably, however, daily diaries (e.g., SofferDudek and Shahar, 2011), are less biased than self-reporting on the past month or year because reporting is proximal to the experience, thus less distorted by memory. Future research should also examine daily emotion using ecological momentary assessment and relations with GSEs, to investigate directional relationships, perhaps in conjunction with polysomnography. In addition, scoring dream content using blind raters may provide a less biased approach to the assessment of the relation

\footnotetext{
${ }^{2}$ The notion that individuals are unaware of the connection between their GSEs and distress is concordant with the finding that the relationship between sleep experiences and dissociation does not stem from symptom exaggeration (Merckelbach et al., 2015).
} 
between dream themes and psychopathology (e.g., Schredl and Engelhardt, 2001). Still, the field would benefit from the inclusion of basic and experimental research. For example, although psychiatric medications affect dreaming, such examinations are scarce (Tribl et al., 2013). Also, although interventions of lucidity with nightmare re-scripting are probably useful in reducing distress (Gavie and Revonsuo, 2010), such research is in its infancy.

Additionally, more work is needed in order to integrate the literatures on nocturnal consciousness and non-REM parasomnias; these also represent mixed sleep-wake states, relate to dissociation (Mahowald and Schenck, 2001), and to psychopathological distress (Schenck and Mahowald, 2005). It is yet to be determined why stress should affect deep sleep in one individual (bringing about unremembered behavioral episodes), and dreaming consciousness in another (resulting in unusual nocturnal cognitions). Possibly, the extent of dissociative tendencies may be responsible; this remains an issue for future research to explore. Future studies should also work to integrate quantitative and qualitative nocturnal characteristics. For example, severely depressed individuals have more REM at the beginning of the night, but less of it during morning-time (Vogel et al., 1980), when dreaming is most frequent; Indeed, their dreaming is impoverished (Cartwright, 2010), suggesting that a complete quantitative-qualitative picture may elucidate psychopathology.

Finally, another limitation of some of the studies reviewed is their correlational design, limiting the ability to draw causal conclusions. However, several studies employed prospectivelongitudinal paradigms, assessing change and examining directionality; these studies showed that GSEs both follow and prospectively predict change in psychopathology. Also, one study implemented time-lag analysis on daily data, showing that GSEs followed stress, rather than vice versa (Soffer-Dudek and Shahar, 2011). Further, research should establish whether GSEs are a consequence of emotional distress, a cause, or both. Several

\section{REFERENCES}

Agargun, M. Y., and Cartwright, R. (2003). REM sleep, dream variables and suicidality in depressed patients. Psychiatry Res. 119, 33-39. doi: 10.1016/S0165-1781(03)00111-2

American Psychiatric Association (2013). Diagnostic and Statistical Manual of Mental Disorders (DSM-5), 5th Edn. Arlington, VA: APA. doi: 10.1176/appi.books.9780890425596

Benca, R. M., Obermeyer, W. H., Thisted, R. A., and Gillin, J. C. (1992). Sleep and psychiatric-disorders: a meta-analysis. Arch. Gen. Psychiatry. 49, 651-668. doi: 10.1001/archpsyc.1992.01820080059010

Blagrove, M., and Hartnell, S. J. (2000). Lucid dreaming: associations with internal locus of control, need for cognition and creativity. Pers. Indiv. Differ. 28, 41-47. doi: 10.1016/s0191-8869(99)00078-1

Blagrove, M., and Tucker, M. (1994). Individual differences in locus of control and the reporting of lucid dreaming. Pers. Indiv. Differ. 16, 981-984. doi: 10.1016/0191-8869(94)90242-9

Brosschot, J. F., Van Dijk, E., and Thayer, J. F. (2007). Daily worry is related to low heart rate variability during waking and the subsequent nocturnal sleep period. Int. J. Psychophysiol. 16, 981-984. doi: 10.1016/j.ijpsycho.2006.07.016

Bryant, R. A., Wyzenbeek, M., and Weinsten, J. (2011). Dream rebound of suppressed emotional thoughts: the influence of cognitive load. Conscious. Cogn. 20, 515-522. doi: 10.1016/j.concog.2010.11.004 researchers have assigned an active role of emotion regulation and modification to dreaming (e.g., Hartmann, 1998; Levin and Nielsen, 2009; Cartwright, 2010) and more generally, to REM sleep (e.g., Genzel et al., 2015). GSEs may either reflect impaired regulation, or act as a dysregulating force in and of themselves. For example, dreams may engender predictive coding (Kirov, 2016), functioning as a "virtual-reality generator" (Hobson et al., 2014); GSEs may actively impede this mechanism, by introducing external arousal and awareness instead of fully delusional and endogenous REM dreams. Indeed, emotional arousal has been conceptualized as energetic impingement, which brings about both psychopathological symptoms and dream imagery, as the brain's attempt to reduce free energy (Hopkins, 2016); GSEs may reflect impinged-upon dreaming, which joins forces with waking mechanisms to create psychopathological disorders.

In conclusion, some unusual nocturnal experiences seem to be "waking" processes entering sleep states. They increase in frequency during stressful periods, and may be viewed as sleep disruptions. Some of these phenomena are widely accepted as sleep disturbances (e.g., nightmares), whereas others are regarded as esoteric or are hardly regarded at all (e.g., falling dreams, false awakenings). Although GSEs and other dream characteristics are associated with psychopathological symptoms, qualitative aspects of sleep are not included in most diagnostic criteria and rarely routinely assessed. Unusual nocturnal consciousness characteristics are an important way to explore sleep impairment in psychopathology. This relatively under-researched field may lead to novel insights regarding nocturnal emotional states and the underpinnings of consciousness, and may contribute to understanding the specificity of sleep impairment in different psychopathological disorders.

\section{AUTHOR CONTRIBUTIONS}

NSD is solely responsible for the conception, literature review, and writing of this paper.

Cartwright, R. (2010). The Twenty-Four Hour Mind: The Role of Sleep and Dreaming in Our Mental Lives. Oxford: Oxford University Press.

Casement, M. D., and Swanson, L. M. (2012). A meta-analysis of imagery rehearsal for post-trauma nightmares: effects on nightmare frequency, sleep quality, and posttraumatic stress. Clin. Psychol. Rev. 32, 566-574. doi: 10.1016/j.cpr.2012.06.002

Cavallotti, S., Castelnovo, A., Ranieri, R., and D'agostino, A. (2014). Stability of cognition across wakefulness and dreams in psychotic major depression. Psychiatry Res. 216, 31-36. doi: 10.1016/j.psychres.2014.01.033

Chouinard, S., Poulin, J., Stip, E., and Godbout, R. (2004). Sleep in untreated patients with schizophrenia: a meta-analysis. Schizophr. Bull. 30, 957-967. doi: 10.1093/oxfordjournals.schbul.a007145

Corlett, P. R., Canavan, S. V., Nahum, L., Appah, F., and Morgan, P. T. (2014). Dreams, reality and memory: confabulations in lucid dreamers implicate reality-monitoring dysfunction in dream consciousness. Cogn. Neuropsychiatry 19, 540-553. doi: 10.1080/13546805.2014.932685

Cortese, S., Faraone, S. V., Konofal, E., and Lecendreux, M. (2009). Sleep in children with attention-deficit/ hyperactivity disorder: meta-analysis of subjective and objective studies. J. Am. Acad. Child Adolesc. Psychiatr. 48, 894-908. doi: 10.1097/chi.0b013e3181ae09c9

Cukrowicz, K. C., Otamendi, A., Pinto, J. V., Bernert, R. A., Krakow, B., and Joiner, T. E. Jr. (2006). The impact of insomnia and sleep disturbances on depression and suicidality. Dreaming 16, 1-10. doi: 10.1037/1053-0797.16.1.1 
D'Agostino, A., Limosani, I., and Scarone, S. (2012). The dreaming brain/mind: a role in understanding complex mental disorders? Front. Psychiatry 3:3. doi: 10.3389/fpsyt.2012.00003

D’Agostino, A., Aletti, G., Carboni, M., Cavallotti, S., Limosani, I., Manzone, M., et al. (2013). Are delusional contents replayed during dreams? Conscious. Cogn. 22, 708-715. doi: 10.1016/j.concog.2013.04.006

Dahl, R. E. (1996). The regulation of sleep and arousal: development and psychopathology. Dev. Psychopathol. 8, 3-27. doi: 10.1017/S0954579400006945

Davis, J. L., Pruiksma, K. E., Rhudy, J. L., and Byrd, P. (2011). A comparison of lifelong and posttrauma nightmares in a civilian trauma sample: nightmare characteristics, psychopathology, and treatment outcome. Dreaming 21, 70-80. doi: $10.1037 / \mathrm{a} 0022862$

Díaz-Román, A., Perestelo-Pérez, L., and Buela-Casal, G. (2015). Sleep in obsessive-compulsive disorder: a systematic review and meta-analysis. Sleep Med. 16, 185-197. doi: 10.1016/j.sleep.2015.03.020

Duke, T., and Davidson, J. (2002). Ordinary and recurrent dream recall of active, past and non-recurrent dreamers during and after academic stress. Dreaming 12, 185-197. doi: 10.1023/A:1021152411010

Edwards, L. J., Muller, K. E., Wolfinger, R. D., Qaqish, B. F., and Schabenberger, O. (2008). An R2 statistic for fixed effects in the linear mixed model. Stat. Med. 27, 6137-6157. doi: 10.1002/sim.3429

Elrod, M. G., and Hood, B. S. (2015). Sleep differences among children with autism spectrum disorders and typically developing peers: a meta-analysis. J. Dev. Behav. Pediatr. 36, 166-177. doi: 10.1097/DBP.0000000000000140

Fassler, O., Knox, J., and Lynn, S. J. (2006). The Iowa sleep experiences survey: hypnotizability, absorption, and dissociation. Pers. Indiv. Differ. 41, 675-684. doi: $10.1016 /$ j.paid.2006.03.007

Gavie, J., and Revonsuo, A. (2010). The future of lucid dreaming treatment: Commentary on "The neurobiology of consciousness: lucid dreaming wakes up” by J. Allan Hobson. Int. J. Dream Res. 3, 13-15.

Genzel, L., Spoormaker, V., Konrad, M., and Dresler, M. (2015). The role of rapid eye movement sleep for amygdala-related memory processing. Neurobiol. Learn. Mem. 122, 110-121. doi: 10.1016/j.nlm.2015.01.008

Giesbrecht, T., and Merckelbach, H. (2004). Subjective sleep experiences are related to dissociation. Pers. Indiv. Differ. 37, 1341-1345. doi: 10.1016/j.paid.2004.01.004

Giesbrecht, T., and Merckelbach, H. (2006a). Dreaming to reduce fantasy? Fantasy proneness, dissociation, and subjective sleep experiences. Pers. Indiv. Differ. 41, 697-706. doi: 10.1016/j.paid.2006.02.015

Giesbrecht, T., and Merckelbach, H. (2006b). Dissociatieve symptomen en slaap [Dissociative symptoms and sleep]. Pers. Tijdschr. Psychiatr. 48, 207-215.

Giesbrecht, T., Jongen, E. M. M., Smulders, F. T. Y., and Merckelbach, H. (2006). Dissociation, resting EEG, and subjective sleep experiences in undergraduates. J. Nerv. Ment. Dis. 194, 362-368. doi: 10.1097/01.nmd.0000217821.18908.bf

Giesbrecht, T., Lynn, S. J., Lilienfeld, S. O., and Merckelbach, H. (2008). Cognitive processes in dissociation: an analysis of core theoretical assumptions. Psychol. Bull. 134, 617-647. doi: 10.1037/0033-2909.134.5.617

Gottesmann, C. (2006). The dreaming sleep stage: a new neurobiological model of schizophrenia? Neuroscience 140, 1105-1115. doi: 10.1016/j.neuroscience.2006.02.082

Hall, M., Thayer, J. F., Germaine, A., Moul, D., Vasko, R., Puhl, M., et al. (2007). Psychological stress is associated with heightened physiological arousal during NREM sleep in primary insomnia. Beha. Sleep. Med. 5, 178-193. doi: 10.1080/15402000701263221

Hartmann, E. (1991). Boundaries in the Mind: A New Psychology of Personality. New York, NY: Basic Books.

Hartmann, E. (1998). Nightmare after trauma as paradigm for all dreams: a new approach to the nature and functions of dreaming. Psychiatry Interpers. Biol. Process. 61, 223-238. doi: 10.1080/00332747.1998.11024834

Hobson, A., Hong, C. C. H., and Friston, K. (2014). Virtual reality and consciousness inference in dreaming. Front. Psychol. 5:1133. doi: 10.3389/fpsyg.2014.01133

Hopkins, J. (2016). Free energy and virtual reality in neuroscience and psychoanalysis: a complexity theory of dreaming and mental disorder. Front. Psychol. 7:922. doi: 10.3389/fpsyg.2016.00922

Kirov, R. (2016). Editorial: Brain oscillations and predictive coding in the context of different conscious states and sleep-wake cycle: implications for decision making and psychopathology. Front. Psychol. 7:1768 doi: 10.3389/fpsyg.2016.01768

Knox, J., and Lynn, S. J. (2014). Sleep experiences, dissociation, imaginal experiences, and schizotypy: the role of context. Conscious. Cogn. 23, 22-31. doi: 10.1016/j.concog.2013.10.007

Koffel, E. (2011). Further validation of the Iowa sleep disturbances inventory. Psychol. Assess. 23, 587-598. doi: 10.1037/a0022818

Koffel, E., and Watson, D. (2009). Unusual sleep experiences, dissociation, and schizotypy: evidence for a common domain. Clin. Psychol. Rev. 29, 548-559. doi: 10.1016/j.cpr.2009.06.004

Koffel, E., and Watson, D. (2010). Development and initial validation of the Iowa sleep disturbances inventory. Assessment 17, 423-439. doi: 10.1177/1073191110362864

Kröner-Borowik, T., Gosch, S., Hansen, K., Borowik, B., Schredl, M., and Steil, R. (2013). The effects of suppressing intrusive thoughts on dream content, dream distress, and psychological parameters. J. Sleep Res. 22, 600-604. doi: $10.1111 /$ jsr. 12058

Kroth, J., Thompson, L., Jackson, J., Pascali, L., and Ferreira, M. (2002). Dream characteristics of stock brokers after a major market downturn. Psychol. Rep. 90, 1097-1100. doi: 10.2466/pr0.2002.90.3c.1097

Kucukgoncu, S., Aktar, E., Erginbas, E., Bestepe, E. E., Calikusu, C., Algin, F., et al. (2010). Relationship between dissociative experiences, abnormal sleep experiences, and sleep quality in undergraduate students. Düsünen Adam. 23, 77-84. doi: 10.5350/DAJPN2010230201

Lange, R., Thalbourne, M. A., Houran, J., and Storm, L. (2000). The revised transliminality scale: reliability and validity data from a Rasch top-down purification procedure. Conscious. Cogn. 9, 591-617. doi: 10.1006/ccog.2000.0472

Levin, R. (1998). Nightmares and schizotypy. Psychiatry Interpers. Biol. Process. 61, 206-216.

Levin, R., and Nielsen, T. (2009). Nightmares, bad dreams, and emotion dysregulation: a review and new neurocognitive model of dreaming. Curr. Dir. Psychol. Sci. 18, 84-88. doi: 10.1111/j.1467-8721.2009.01614.x

Mahowald, M. W., and Schenck, C. H. (2001). Evolving concepts of human state dissociation. Arch. Ital. Biol. 139, 269-300.

Malinowski, J. E. (2016). Dreaming and personality: wake-dream continuity, thought suppression, and the Big Five Inventory. Conscious. Cogn. 38, 9-15. doi: 10.1016/j.concog.2015.10.004

McNally, R. J., and Clancy, S. A. (2005). Sleep paralysis in adults reporting repressed, recovered, or continuous memories of childhood sexual abuse. J. Anxiety Disord. 19, 595-602. doi: 10.1016/j.janxdis.2004.05.003

McNamara, P., Johnson, P., McLaren, D., Harris, E., Beauharnais, C., and Auerbach, S. (2010). REM and NREM sleep mentation. Int. Rev. Neurobiol. 92 69-86. doi: 10.1016/S0074-7742(10)92004-7

Merckelbach, H., Giesbrecht, T., van Heugten-van der Kloet, D., de Jong, J., Meyer, T., and Rietman, K. (2015). The overlap between dissociative symptoms and symptom over-reporting. Eur. J. Psychiatry 29, 165-172. doi: 10.4321/S0213-61632015000300001

Ng, T. H., Chung, K. F., Ho, F. Y. Y., Yeung, W. F., Yung, K. P., and Lam, T. H. (2015). Sleep-wake disturbance in interepisode bipolar disorder and high-risk individuals: a systematic review and meta-analysis. Sleep Med. Rev. 20, 46-58. doi: 10.1016/j.smrv.2014.06.006

Nofzinger, E. A., Buysse, D. J., Germain, A., Price, J. C., Miewald, J. M., and Kupfer, D. J. (2004). Functional neuroimaging evidence for hyperarousal in insomnia. Am. J. Psychiat. 161, 2126-2128. doi: 10.1176/appi.ajp.161.11.2126

Nota, J. A., Sharkey, K. M., and Coles, M. E. (2015). Sleep, arousal, and circadian rhythms in adults with obsessive-compulsive disorder: a metaanalysis. Neurosci. Biobehav. Rev. 51, 100-107. doi: 10.1016/j.neubiorev.2015 01.002

Ohayon, M. M. (2000). Prevalence of hallucinations and their pathological associations in the general population. Psychiatry Res. 97, 153-164. doi: 10.1016/S0165-1781(00)00227-4

Ohayon, M. M., Priest, R. G., Caulet, M., and Guilleminault, C. (1996). Hypnagogic and hypnopompic hallucinations: pathological phenomena? Br. J. Psychiatry 169, 459-467. doi: 10.1192/bjp.169.4.459

Patrick, A., and Durndell, A. (2004). Lucid dreaming and personality: a replication. Dreaming 14, 234-239. doi: 10.1037/1053-0797.14.4.234 
Perlis, M. L., Smith, M. T., Andrews, P. J., Orff, H., and Giles, D. E. (2001). Beta/gamma EEG activity in patients with primary and secondary insomnia and good sleeper controls. Sleep 24, 110-117. doi: 10.1093/sleep/24.1.110

Pigeon, W. R., Pinquart, M., and Conner, K. (2012). Meta-analysis of sleep disturbance and suicidal thoughts and behaviors. J. Clin. Psychiatry 73, e1160e1167. doi: 10.4088/jcp.11r07586

Schenck, C. H., and Mahowald, M. W. (2005). Rapid eye movement and non-REM sleep parasomnias. Prim. Psychiatry 12, 67-74.

Schmidt, R. E., and Gendolla, G. H. E. (2008). Dreaming of white bears: the return of the suppressed at sleep onset. Conscious. Cogn. 17, 714-724. doi: 10.1016/j.concog.2007.09.002

Schredl, M. (2007). Personality correlates of flying dreams. Imagin. Cogn. Pers. 27, 129-137. doi: 10.2190/IC.27.2.d

Schredl, M. (2016). Dreams and nightmares in personality disorders. Curr. Psychiatry Rep. 18:15. doi: 10.1007/s11920-015-0653-2

Schredl, M., and Engelhardt, H. (2001). Dreaming and psychopathology: dream recall and dream content of psychiatric inpatients. Sleep Hypn. 3, 44-54.

Schwartz, S., and Maquet, P. (2002). Sleep imaging and the neuropsychological assessment of dreams. Trends Cogn. Sci. 6, 23-30. doi: 10.1016/S1364-6613(00)01818-0

Sedky, K., Bennett, D. S., and Carvalho, K. S. (2014). Attention deficit hyperactivity disorder and sleep disordered breathing in pediatric populations: a metaanalysis. Sleep Med. Rev. 18, 349-356. doi: 10.1016/j.smrv.2013.12.003

Sjöström, N., Wærn, M., and Hetta, J. (2007). Nightmares and sleep disturbances in relation to suicidality in suicide attempters. Sleep 30, 91-95. doi: $10.1093 /$ sleep/30.1.91

Soffer-Dudek, N. (2016). Sleep-related experiences longitudinally predict elevation in psychopathological distress in young adult Israelis exposed to terrorism. Pers. Individ. Dif. 100, 131-139. doi: 10.1016/j.paid.2015.12.006

Soffer-Dudek, N., and Sadeh, A. (2013). Dream recall frequency and unusual dream experiences in early adolescence: Longitudinal links to behavior problems. J. Res. Adolesc. 23, 635-651. doi: 10.1111/jora.12007

Soffer-Dudek, N., and Shahar, G. (2009). What are sleep-related experiences? Associations with transliminality, psychological distress, and life stress. Conscious. Cogn. 18, 891-904. doi: 10.1016/j.concog.2008.07.007

Soffer-Dudek, N., and Shahar, G. (2010). Effect of exposure to terrorism on sleep-related experiences in Israeli young adults. Psychiatry 73, 264-276. doi: 10.1521 /psyc.2010.73.3.264

Soffer-Dudek, N., and Shahar, G. (2011). Daily stress interacts with trait dissociation to predict sleep-related experiences in young adults. J. Abnorm. Psychol. 120, 719-729. doi: 10.1037/a0022941

Soffer-Dudek, N., Lassri, D., Soffer-Dudek, N., and Shahar, G. (2015). Dissociative absorption: an empirically unique, clinically relevant, dissociative factor. Conscious. Cogn. 36, 338-351. doi: 10.1016/j.concog.2015.07.013

Soffer-Dudek, N., Shalev, H., Shiber, A., and Shahar, G. (2011a). Role of severe psychopathology in sleep-related experiences: a pilot study. Dreaming 21, 148-156. doi: 10.1037/a0022865

Soffer-Dudek, N., Wertheim, R., and Shahar, G. (2011b). Lucid dreaming and resilience in the face of exposure to terrorism. J. Trauma. Stress 24, 125-128. doi: 10.1002/jts.20601

Sponheim, S. R., Clementz, B. A., Iacono, W. G., and Beiser, M. (1994). Resting EEG in first episode and chronic schizophrenia. Psychophysiology 31, 37-43. doi: 10.1111/j.1469-8986.1994.tb01023.x

Spoormaker, V. I., and Montgomery, P. (2008). Disturbed sleep in post-traumatic stress disorder: secondary symptom or core feature? Sleep Med. Rev. 12, 169-184. doi: 10.1016/j.smrv.2007.08.008

Taylor, F., and Bryant, R. A. (2007). The tendency to suppress, inhibiting thoughts, and dream rebound. Behav. Res. Ther. 45, 163-168. doi: 10.1016/j.brat.2006.01.005

Terhune, D. B. (2009). The incidence and determinants of visual phenomenology during out-of-body experiences. Cortex 45, 236-242. doi: 10.1016/j.cortex.2007.06.007

Tribl, G. G., Wetter, T. C., and Schredl, M. (2013). Dreaming under antidepressants: a systematic review on evidence in depressive patients and healthy volunteers. Sleep Med. Rev. 17, 133-142. doi: 10.1016/j.smrv.2012.05.001

Van Der Kloet, D., Giesbrecht, T., Franck, E., Van Gastel, A., De Volder, I., Van Den Eede, F., et al. (2013). Dissociative symptoms and sleep parameters-an all-night polysomnography study in patients with insomnia. Compr. Psychiat. 54, 658-664. doi: 10.1016/j.comppsych.2012.12.025 van der Kloet, D., Giesbrecht, T., Lynn, S. J., Merckelbach, H., and de Zutter, A. (2012a). Sleep normalization and decrease in dissociative experiences: evaluation in an inpatient sample. J. Abnorm. Psychol. 121, 140-150. doi: 10.1037/a0024781

van der Kloet, D., Merckelbach, H., Giesbrecht, T., and Lynn, S. J. (2012b). Fragmented sleep, fragmented mind: the role of sleep in dissociative symptoms. Perspect. Psychol. Sci. 7, 159-175. doi: 10.1177/1745691612437597

van der Kolk, B., Blitz, R., Burr, W., Sherry, S., and Hartmann, E. (1984). Nightmares and trauma: a comparison of nightmares after combat with lifelong nightmares in veterans. Am. J. Psychiat. 141, 187-190. doi: 10.1176/ajp.141.2.187

van Heugten-van der Kloet, D., Cosgrave, J., Merckelbach, H., Haines, R., Golodetz, S., and Lynn, S. J. (2015a). Imagining the impossible before breakfast: the relation between creativity, dissociation, and sleep. Front. Psychol. 6:324. doi: 10.3389/fpsyg.2015.00324

van Heugten-van der Kloet, D., Giesbrecht, T., and Merckelbach, H. (2015b). Sleep loss increases dissociation and affects memory for emotional stimuli. J. Behav. Ther. Exp. Psychiatry 47, 9-17. doi: 10.1016/j.jbtep.2014.11.002

van Heugten-van der Kloet, D., Huntjens, R., Giesbrecht, T., and Merckelbach, H. (2014a). Self-reported sleep disturbances in patients with dissociative identity disorder and post-traumatic stress disorder and how they relate to cognitive failures and fantasy proneness. Front. Psychol. 5:19. doi: 10.3389/fpsyt.2014.00019

Van Heugten-van der Kloet, D., Merckelbach, H., Giesbrecht, T., and Broers, N. (2014b). Night-time experiences and daytime dissociation: a path analysis modeling study. Psychiatry Res. 216, 236-241. doi: 10.1016/j.psychres.2013.12.053

Vissia, E. M., Giesen, M. E., Chalavi, S., Nijenhuis, E. R. S., Draijer, N., Brand, B. L., et al. (2016). Is it trauma- or fantasy-based? Comparing dissociative identity disorder, post-traumatic stress disorder, simulators, and controls. Acta Psychiatr. Scand. 134, 111-128. doi: 10.1111/acps.12590

Vogel, G. W., Vogel, F., McAbee, R., and Thurmond, A. (1980). Improvement of depression by REM sleep deprivation: new findings and a theory. Arch. Gen. Psychiatry 37, 247-253. doi: 10.1001/archpsyc.1980.01780160017001

Voss, U., Holzmann, R., Tuin, I., and Hobson, J. A. (2009). Lucid dreaming: a state of consciousness with features of both waking and non-lucid dreaming. Sleep 32, 1191-1200. doi: 10.1093/sleep/32.9.1191

Watson, D. (2001). Dissociations of the night: Individual differences in sleeprelated experiences and their relation to dissociation and schizotypy. J. Abnorm. Psychol. 110, 526-535. doi: 10.1037/0021-843X.110.4.526

Watson, D. (2003). To dream, perchance to remember: individual differences in dream recall. Pers. Indiv. Differ. 34, 1271-1286. doi: 10.1016/S0191-8869(02)00114-9

Watson, D., Stasik, S. M., Ellickson-Larew, S., and Stanton, K. (2015). Explicating the psychopathological correlates of anomalous sleep experiences. Psychol. Conscious. 2, 57-58. doi: 10.1037/cns0000038

Wegner, D. (1994). Ironic process of mental control. Psychol. Rev. 101, 34-52. doi: 10.1037/0033-295X.101.1.34

Wegner, D. M., Wenzlaff, R. M., and Kozak, M. (2004). Dream rebound: the return of suppressed thoughts in dreams. Psychol. Sci. 15, 232-236. doi: 10.1111/j.0963-7214.2004.00657.x

Wenzlaff, R. M., and Wegner, D. M. (2000). Thought suppression. Annu. Rev. Psychol. 51, 59-91. doi: 10.1146/annurev.psych.51.1.59

Zadra, A. L., O’Brien, S. A., and Donderi, D. C. (1997-1998). Dream content, dream recurrence and well-being: a replication with a younger sample. Imagin. Cogn. Pers. 17, 293-311.

Zadra, A., and Donderi, D. C. (2000). Nightmares and bad dreams: their prevalence and relationship to well-being. J. Abnorm. Psychol. 109, 273-281. doi: 10.1037/0021-843X.109.2.273

Conflict of Interest Statement: The author declares that the research was conducted in the absence of any commercial or financial relationships that could be construed as a potential conflict of interest.

Copyright (C) 2017 Soffer-Dudek. This is an open-access article distributed under the terms of the Creative Commons Attribution License (CC BY). The use, distribution or reproduction in other forums is permitted, provided the original author(s) or licensor are credited and that the original publication in this journal is cited, in accordance with accepted academic practice. No use, distribution or reproduction is permitted which does not comply with these terms. 